\title{
A Faith Diplomacy de Xi Jinping: as implicações político-religiosas do acordo provisório sobre a nomeação dos bispos católicos na China
}

Xi Jinping's Faith Diplomacy: The Political-Religious Implications of the Interim Agreement on the Appointment of Catholic Bishops in China

La diplomacia de fe de Xi Jinping: las implicaciones político-religiosas del acuerdo provisional sobre el nombramiento de los obispos católicos en China

Anna Carletti ${ }^{1}$

DOI: $10.5752 /$ P.1809-6182.2019v13n3p24

Recebido em: 16 de junho de 2019

Aceito em: 30 de setembro de 2019

\begin{abstract}
Resumo
$O$ artigo visa identificar os motivos que levaram o atual governo de Pequim a assinar um acordo provisório com a Santa Sé aceitando sua participação na nomeação dos bispos chineses. A pesquisa pode ser enquadrada no âmbito das análises de Politica Externa.

Palavras-chave: China. Santa Sé. Diplomacia da Fé.

Abstract

The article aims to identify the reasons that led the current Beijing government to sign an interim agreement with the Holy See accepting their participation in the appointment of the Chinese bishops. The research can be framed within the scope of Foreign Policy analysis. Keywords: China. Holy See. Diplomacy of the Faith.

\section{Resumen}

El artículo tiene como objetivo identificar las razones que llevaron al actual gobierno de Beijing a firmar un acuerdo provisional con la Santa Sede aceptando su participación en el nombramiento de los obispos chinos. La investigación puede enmarcarse dentro del alcance del análisis de la politica exterior.

Palabras clave: China. Santa Sede. Diplomacia de la fe.
\end{abstract}

\footnotetext{
1 Doutora em História (2207) pela UFRGS e Pós-Doutora em Ciência Política (2011) pela mesma instituição. Professora Associada do curso de Relações Internacionais da Universidade Federal do Pampa (UNIPAMPA) e Professora da Pós-Graduação de Relaçôes Internacionais da UEPB. Residente no Brasil em Santana do Livramento (RS). https://orcid.org/0000-0002-7998-4457
} 


\section{Introdução}

Em setembro de 2018, a Republica Popular da China (RPCh), sob o comando de Xi Jinping e a Santa Sé liderada pelo Papa Francisco assinaram um acordo provisório sobre a espinhosa questáo da nomeação dos bispos chineses. Tal acordo foi considerado por estudiosos da China e Santa Sé (SISCI, 2018; CHAMBON, 2018), como um evento histórico dentro das relaçôes entre o gigante da Ásia e o menor estado do mundo, a Cidade do Estado do Vaticano, base territorial da Santa Sé, única instituição religiosa reconhecida como sujeito internacional que mantém relaçôes diplomáticas com cerca de 180 países. A desconfiança chinesa em relação à prerrogativa do Papa, chefe de um estado estrangeiro, de nomear figuras públicas atuantes no território chinês, como são os bispos católicos, gerou desde o início das relaçóes entre os dois atores estatais, discussões sobre as modalidades dessas nomeaçóes. A partir da proclamação da República Popular da China, em 1949, sob a liderança de Mao Zedong e da ruptura das relações diplomáticas com a Santa Sé em 1951, quando da fuga para Taiwan do então núncio apostólico da Santa Sé, Antonio Riberi, tal questão se tornou uma dificuldade aparentemente insuperável pela convicção por parte do governo comunista de que a nomeação dos bispos chineses por parte do Papa constituísse uma ingerência política indevida e uma violação da soberania do Estado chinês.

Com efeito, o governo de Pequim não conseguia entender porque um chefe de um Estado estrangeiro, a saber, o estado da Cidade do Vaticano, reivindicava para si o direito de nomear bispos chineses que operariam dentro do território chinês. De acordo com a visão das autoridades de Pequim da época, isso poderia configurar-se como uma tentativa de interferir na construção da Nova China.
A partir do pontificado de Joáo XXIII, que assumiu o comando da Santa Sé em 1958, registraram-se tentativas de diálogo instauradas mais por iniciativa da Santa Sé que do próprio governo chinês visando retomar as relaçóes diplomáticas com a RPCh. Contudo, as demandas chinesas para que as relaçóes fossem retomadas baseava-se sempre em dois pontos considerados condiçôes sine qua non para a retomada do diálogo: a primeira que dizia respeito à cessão de ingerência por parte da Santa Sé no que dizia respeito à nomeação dos bispos chineses e a segunda que a Santa Sé rompesse suas relações diplomáticas com Taiwan.

Em realidade, a repetição quase que retórica dessas duas demandas consideradas necessárias para que se iniciasse um diálogo com a Santa Sé pareciam um pretexto por parte do governo chinês para esconder a falta de interesse por parte das autoridades de Pequim em retomar relaçóes diplomáticas com um estado cujo interesse nacional é predominantemente ligado ao fator religioso e que náo poderia oferecer nada que fosse, naquele momento, de interesse do governo chinês.

Contudo, quando da eleição do Papa Francisco contemporânea à chegada de poder de $\mathrm{Xi}$ Jinping à presidência da República Popular da China, pareceu que algo mudara. $\mathrm{O}$ novo presidente começou a prestar mais atençáo aos apelos lançados pelo Papa Francisco para que tivesse início uma nova rodada de negociaçôes entre os dois interlocutores. As missivas da Santa Sé, pela primeira vez, obtiveram resposta por parte das autoridades de Pequim diretamente ou indiretamente. $\mathrm{O}$ acordo provisório assinado em setembro de 2018 pode ser considerado o resultado visível desta mudança por parte do governo chinês.

Frente a isso, o artigo visa identificar os motivos que levaram o governo de Pequim a assinar um acordo provisório com a Santa Sé aceitando 
sua participação na nomeação dos bispos chineses. A pesquisa pode ser enquadrada no âmbito das análises de Política Externa, onde elementos como cultura e religiáo, em particular a chamada Faith Diplomacy emerge como um fator condicionante na construção das relaçooes de força no cenário internacional (LEIGHT, 2011).

De acordo com Zhang (2011), os objetivos da Diplomacia da Fé chinesa incluem promover uma compreensão internacional e aceitação das políticas religiosas da China, defendendo as atuaçôes chinesas para com a religião, melhorando a imagem da China no exterior, contribuindo desta forma à construção de um mundo harmonioso.

$\mathrm{O}$ uso da Faith Diplomacy por parte de Xi Jinping, desde o início de seu primeiro mandato político, leva à pergunta principal de nossa pesquisa: o que mudou na política externa chinesa para que Xi Jinping aceitasse assinar um acordo provisório com a Santa Sé para nomeação dos bispos chineses?

A hipótese a ser verificada é que a República Popular da China na sua atual busca de extroversão internacional esteja fazendo uso não apenas de tradicionais instrumentos de hard power, mas que esteja apostando no uso de soft power (ou poder suave, poder branco) em sua política externa principalmente para mitigar as inevitáveis perceçôes suscitadas em seus vizinhos frente à sua expansão geopolítica e militar. Neste contexto, nos parece que o presidente $\mathrm{Xi}$ Jinping tenha identificado a Santa Sé como um sujeito internacional dotado de grande influência no âmbito mundial e que poderia legitimar e apoiar sua busca por ocupar um lugar de destaque no atual sistema internacional.

Para testar esta hipótese, na primeira parte do artigo será analisado o conceito da Faith Diploma$c y$ - considerada parte do emprego do soft power-e seu uso por parte do governo chinês aplicando-o especificamente ao estudo de caso das relaçôes do governo chinês com a Santa Sé. Na segunda parte do artigo, serão evidenciados os principais avanços que ocorreram nas relaçôes entre a RPCh e a Santa Sé a partir de 2013, sublinhando as inéditas iniciativas de aproximação tomadas pelo governo de Pequim que pela primeira vez decidiu responder aos apelos da Santa Sé. A terceira e última parte do artigo será dedicada à análise das implicaçóes político-religiosas do acordo provisório assinado em 22 de setembro de 2018 apresentando tampem as conclusóes da pesquisa.

O estudo envolverá a análise qualitativa de fontes primárias e secundárias quais documentos oficiais do governo chinês e e da Santa Sé, assim como estudos de intelectuais chineses e ocidentais sobre as relaçôes entre os dois estados.

\section{A Faith Diplomacy de Xi Jinping}

Desde sua chegada ao poder em 2013, o governo de $\mathrm{Xi}$ Jinping diferenciou-se dos governos que o precederam, sobretudo pelo forte sentimento nacionalista que caracterizou seus primeiros atos políticos, principalmente no que se refere a sua política externa. Ao lançar o lema de seu governo "O sonho chinês" que implicaria no Ressurgimento da China, o líder da quinta geração política chinesa mostrou claramente sua intençáo de afastar-se da política externa de baixo perfil inaugurada pelo Deng Xiaoping na década de 1980 e seguida pelos sucessivos lideres políticos até a chegada de Xi Jinping (BATES, 2017). De acordo com Estebam (2017, p. 3, traduçâo nossa) ${ }^{2}$, "Assim como acontece

\footnotetext{
$2 \mathrm{Al}$ igual que sucede en otras áreas, también en política exterior Xi Jinping ha mostrado mayor capacidad de liderazgo que sus dos inmediatos predecesores (Jiang Zemin y Hu Jin-
} 
em outras áreas, também em política externa $\mathrm{Xi}$ Jinping mostrou maior capacidade de liderança que seus imediatos predecessores (Jiang Zemin e Hu Jintao) proporcionando uma virada diplomática de uma envergadura sem precedentes desde os tempos de Deng”.

Para alcançar o objetivo de levar a China a reocupar um lugar de destaque dentro do sistema internacional, Xi Jinping está fazendo uso tanto de instrumentos tradicionais de poder conhecidos como hard power que de outros meios de fortalecimento de sua imagem no âmbito internacional que Joseph Nye batizou de soft power (ou poder suave, poder branco). De acordo com Becard (2019), o conceito de soft power criado pelo Nye em 1990 foi introduzido na China por Wang Huning que definiu este conceito como a cultura que representa o poder de um país. Com o passar do tempo, porém, debates acadêmicos na China apontaram à necessidade de traduzir o conceito de soft power de Nye para um conceito de soft power com características chinesas. Isso resultou em uma alteração do conceito original que passou a ser chamado de Chinese Soft Power (GLASER, MURPHY, 2009). Mesmo concordando com a definição de Nye que sublinhava o poder de atraçâo de um país por meio da cultura, política externa e outros valores, os acadêmicos chineses defendiam uma visão mais abrangente do conceito chinês de soft power, envolvendo fatores como o desenvolvimento econômico da China e o Consenso de Pequim como característica proeminente do soft power.

Acadêmicos chineses enfatizam que o sucesso
socioeconômico da China e sua experiência
com o desenvolvimento dão oportunidade
para o poder brando. Relaçóes diplomáticas

tao) propiciando un giro diplomático de una envergadura sin precedentes desde los tiempos de Deng. sofisticadas e comportamento respeitável na arena internacional também são endossadas para melhorar o poder brando de um país. (OSMAN, 2017, p. 6, tradução nossa) ${ }^{3}$.

Conforme Becard, a promoção do soft power como meio de melhorar a imagem chinesa frente à comunidade internacional foi incentivada pelo governo de Pequim desde a década de 1990, sobretudo após os acontecimentos da Praça Tian Anmen, tendo visível aumento em 2008, após o sucesso das Olimpíadas de Pequim (2019).

No âmbito deste esforço de implementar o que foi chamada de diplomacia cultural, encontramos também o conceito bastante recente de Faith Diplomacy (Diplomacia da Fé). Em 2001, o então presidente Jiang Zemin pela primeira vez reconheceu que a religião poderia agir como força estabilizadora na sociedade e, assim, pode ser considerada uma força positiva para o desenvolvimento nacional (LEUNG, 2005). De acordo com Chu (2011, p. 53, tradução nossa) $)^{4}$ "as religióes são consideradas um recurso diplomático por parte do governo chinês".

Conforme Zhang (2011), na China, a Diplomacia da Fé é um esforço conjunto de diferentes agências governamentais coordenado pelo Escritório Estatal de Assuntos Religiosos, O Escritório de Informação do Conselho Estatal, o Ministério da Cultura, O Departamento do Trabalho da Frente Unida do Partido Comunista assim como o Conselho Nacional das Religióes.

No que diz respeito às relaçóes com o a Santa Sé, desde que os canais de diálogos foram

\footnotetext{
3 Chinese academics stress that China's socioeconomic success and its experience with development give opportunity for soft power. Sophisticated diplomatic relations and respectable behavior in the international arena are also endorsed to improve a nation's soft power.

4 "religions are considered by the Chinese government a diplomatic resource".
} 
reabertos, a saber, durante o pontificado de João Paulo II, nunca foram registrados avanços significativos como ocorreu a partir de 2013, ano em que Xi Jinping assumiu a presidência da RPCh e o Papa Francisco foi eleito novo pontífice da Igreja Católica.

\section{Os principais avanços nas relações China-Santa Sé (2013-2018)}

A partir do primeiro mandato dos dois líderes, o da China, e o da Santa Sé, é possível identificar passos importantes dados pelo governo de Pequim em direção a uma possível normalização das relaçôes com a Santa Sé, fazendo justamente uso deste instrumento de soft power que é a Faith Diplomacy.

O primeiro passo ocorreu no segundo ano do pontificado de Francisco quando Pequim permitiu que o Papa Francisco entrasse no espaço aéreo chinês durante seu vôo para a Coreia do Sul. A permissão se repetiu outras duas vezes durante as viagens realizadas pelo Papa na Ásia.

Mas a virada e a aceleração na aproximação entre as duas partes foi identificada pelo professor da Renmin University de Pequim, Francesco Sisci durante a visita que os dois lideres, o presidente Xi Jinping e o Papa Francisco fizeram no mesmo período aos Estados Unidos. De acordo com Sisci, na sua visita aos EUA, Xi Jinping esperava receber a máxima atençáo dos meios de comunicação norte americanos assim como ocorrera nas visitas dos seus predecessores. Contudo, ele não havia calculado que a visita do Papa poderia ofuscar sua presença no país. Na visão de Sisci $(2018$, p. 2) “esse fato fez com que se entendesse de forma concreta o que alguns, na China, já diziam há algum tempo, mas que não era entendido pela liderança, isto é, o super poder suave do Papado". Xi Jinping percebeu, de acordo com a análise do Sisci (2018), que a questão China-Santa Sé até então considerado como um assunto domestico, era, ao contrário, uma questão relacionada à política externa. É interessante o raciocínio que o Sisci apresenta sobre a mudança da percepção chinesa a propósito das relaçóes China-Santa Sé,

Se a Santa Sé é a super potência, o pensamento se torna: somos nós, chineses que devemos nos inserir nesse mundo onde o Vaticano consegue ser tão importante. Devemos ter um senso de urgência. Em segundo lugar, chega também um cálculo de risco. Se o Vaticano é tão poderoso, não se trata mais de gerir esses poucos milhôes de católicos chineses. Talvez eles possam nos ajudar, mas talvez até prejudicar nossa posição no mundo. (SISCI, 2018, p. 3).

A entrevista concedida pelo Papa Francisco ao professor Sisci logo depois da visita aos Estados Unidos pareceu confirmar tal percepção. $\mathrm{Na}$ entrevista, o Papa demonstrou grande admiração para com a China definindo-a como um país de grande cultura que não deveria ser temida mas da qual poderíamos aprender, uma nação que poderia dar grande contribuição ao resto da humanidade (SISCI, 2016).

A entrevista teve repercussóes bastante positivas na China sendo replicada e comentada por diversos jornais chineses, incluindo os mais próximos ao governo de Pequim como o Jornal Global Times que comentou em grande medida a entrevista (GLOBAL TIMES, 2016). É importante sublinhar como os jornais próximos ao governo de Pequim e jornais italianos próximos ao Vaticano contribuíram à aproximação das duas partes veiculando as intençôes das respectivas partes em relação à questão. Do lado chinês, jornais próximos ao governo de Pequim, como o já mencionado Global Times usado pelo governo de Pequim para fazer con- 
hecer suas orientaçôes no exterior, publicou, naquele ano 04 artigos $^{5}$ sobre a questão, fato inédito que evidenciou o incremento de interesse da China em relação à questão das relaçôes com a Santa Sé.

Em agosto de 2016, pela primeira vez na história das relações entre China e Santa Sé, o presidente da RPCh respondeu à mensagem de um Papa e enviou de presente uma cópia da Estela Cristã da cidade de Xi'an do século VII. Lembramos que no passado, vários Papas dirigiram missivas aos presidentes chineses, ma nenhum obteve resposta (SISCI, 2018).

Outro passo importante foi o discurso proferido, sempre em 2016, pelo Secretário de Estado da Santa Sé, Pietro Parolin, sobre a importância do papel desenvolvido na China pelo Cardeal Celso Costantini na década de 1920. O discurso pronunciado por um figura politicamente importante (ele seria como o Ministro das Relaçóes Exteriores de um Estado) ressoou positivamente em Pequim principalmente pelo fato do Secretário de Estado evidenciar a renuncia do Costantini a ser nomeado cardeal na China para que fosse nomeado um cardeal chinês, e além disso por ser quem procurou que a Santa Sé conseguisse estreitar relaçôes diplomáticas diretas com a China sem ter que passar pela intermediação da França. A mensagem que chegou aos ouvidos de Pequim era que a Santa Sé apoiava o processo de sinicização da Igreja Católica na China e que não estava ligada a nenhuma potência hegemômica (SISCI, 2018).

Em 29 de outubro de 2016, realizou-se um congresso organizado pela Universidade do Povo de Pequim (Renmin University), fundada por Mao Zedong e voltada principalmente ao estu-

5 Cautious optimis over Sino-Vatican ties (28/12/2016); Between God and Caeser (25/10/2016); LitFest 2016 (10/03/2016); From Rome to Beijing (25/2/16). do de história e política. O discurso de Parolin foi objeto de debate e aprofundamento por parte dos acadêmicos, e considerado fundamental para que as autoridades de Pequim aceitassem discutir um possível acordo em relação à nomeação dos bispos chineses. $\mathrm{Na}$ visão do Sisci, a questão Santa Sé-China se tornou, aos olhos chineses, fator condicionante nas mudanças que estavam ocorrendo no cenário internacional, principalmente as que resultaram da eleição de Donald Trump à presidência dos Estados Unidos. Eles perceberam como a Santa Sé, a diferença dos tempos de João Paulo II, não se alinhara com o poder norte-americano. O Papa Francisco estava seguindo seus objetivos estratégicos independentemente da política dos Estados Unidos e, mesmo assim, sua influencia internacional continuava crescendo. (SISCI, 2018, p. 8).

No mês de junho de 2017, uma visita do diretor do Fundo de Investimentos Culturais da China ao Papa, levou à decisão de realizar uma mostra conjunta dos Museus Vaticanos em Pequim e do Museu da Cidade Proibida em Roma, junto aos Museus Vaticanos. Esta iniciativa da mostra cultural conjunta foi noticiada por parte da China batizando-a de Diplomacia da Arte e foi logo comparada à diplomacia do Ping-pong que levou à normalização das relaçôes entre China e Estados Unidos na década de 1970 (DENG XIAOCI, 2017).

Em seguida, teve a visita do Papa ao Mianmar. Esta visita foi acompanhada com particular interesse pelo governo de Pequim porque Mianmar é um país estrategicamente importante para o projeto chinês das Novas Rotas da Seda. As autoridades chinesas pareceram satisfeitas pelo apoio aberto que o Papa deu à etnia minoritária muçulmana dos Rohingya desafiando os interesses econômicos do governo do Mianmar. A China, contrariamente à sua 
política de não interferência nos assuntos internos de outros países, no caso do Mianmar escolheu uma política de intervenção visando reduzir ao mínimo os fatores de desestabilização que colocariam em risco seus investimentos na região (RAMACHANDRAN, 2017). O Global Times, pela primeira vez publicou uma artigo inteiramente dedicado à visita e um grupo de sacerdotes chineses participaram da missa na catedral de Yangoon exibindo a bandeira nacional da Republica Popular da China e um cartaz com a escrita "Venha logo Santo Padre". Obviamente eles não poderiam fazer este convite se não tivessem tido a permissão oficial do governo comunista. (POPE URGES RESPECT... 2017)

Tais avanços, consequência da decisão do governo de Pequim de mudar o rumo de suas relaçôes com a Santa Sé, teve como resultado concreto a assinatura de um acordo provisório sobre a nomeação dos bispos chinês. Vamos ver na próxima seção do artigo quais as implicaçôes religiôes e políticas deste acordo.

\section{O acordo provisório sobre a nomeação dos bispos: implicações políticas e religiosas nas relações entre Santa Sé e República Popular da China.}

Ao longo desses anos, numerosas visitas de representantes da Santa Sé na China e vice-versa ocorreram para discutir um possível acordo sobre a nomeação dos bispos chineses. Tal questão era considerada inaceitável por parte do governo de Pequim que a interpretou como uma ingerência política por parte de um chefe estrangeiro, o Papa, mesmo que ele se considerasse e fosse considerados pelos demais países da comunidade internacional mais um chefe religioso que político. A polêmica questão da nomeação dos bispos chineses se agravou logo depois da proclamação da República Popular da China em 1949. A China nacionalista e a Santa Sé haviam estabelecido relaçôes diplomáticas em 1942, recebendo em suas respectivas sedes as credenciais de seus embaixadores (CARLETTI, 2008).

Tais relaçôes, porém, foram interrompidas pelo governo comunista em 1951. Os motivos que levaram o governo comunista a romper as relaçôes com a Santa Sé devem ser compreendidos no âmbito da antiga desconfiança chinesa em relação a esta religião estrangeira que por longo tempo se associara aos interesses colonizadores do Ocidente.

$\mathrm{Na}$ época sucessiva ao fim do Segundo Conflito Mundial, o alinhamento da Santa Sé ao lado das potências ocidentais, contra o bloco comunista, foi um elemento ulterior que convenceu Mao Zedong a incluir a Igreja Católica na lista dos inimigos da nova China. Em 1957, o governo de Pequim fundou a Associação Patriótica Católica Chinesa (APCC), para exercer a função de ligação entre o Partido Comunista da China e a Igreja Católica na China. Em 1958, o governo chinês, provavelmente como demonstração de força, por meio da APCC, decidiu consagrar dois bispos católicos independentemente da Santa Sé. Os dois candidatos enviaram às pressas à Santa Sé o pedido de reconhecimento da sua consagração. A Santa Sé, porém, rejeitou as consagrações episcopais julgando-as ilícitas. O governo chinês recebeu tal rejeição como uma espécie de declaração de guerra por parte da Santa Sé e devolveu com a mesma moeda (CARLETTI, 2008).

A partir daquele momento abriu-se uma fenda, não somente entre a Santa Sé e a Chi- 
na, mas no âmbito da própria Igreja Católica na China, que se encontrou dividida. Nascem então, de um lado a Igreja Patriótica ou Oficial constituída por católicos, membros do clero e bispos que aceitaram se registrar junto ao órgão da Associação Patriótica da Igreja Católica e, de outro, a Igreja Clandestina, constituída por católicos, membros do clero e bispos que consideravam tal registro como uma traição à comunhão com o Papado de Roma. O governo chinês sempre considerou os membros da Igreja Clandestina como adversários políticos da RP da China, passíveis de perseguição e prisão, não tanto pelo fato de ser religiosos quanto por se negarem a ser controlados pelo governo de Pequim. Esta divisão dificultou muito as negociaçóes entre a China e Santa Sé até que Bento XVI, em 2007, com uma carta dirigida aos católicos chineses convidou todos os membros da Igreja Chinesa a superar esta divisão e se tornar uma Igreja unida sem distinçôes entre Igreja Oficial e Igreja Clandestina (BENTO XVI, 2007). Francisco seguiu o mesmo caminho incentivando as negociaçôes e encorajando sempre a Igreja chinesa a se unir.

A partir destas premissas histórico-políticas, entende-se o porquê o comunicado oficial da Santa Sé, em 22 de setembro de 20918, anunciando a assinatura de um acordo provisório sobre a nomeação dos bispos despertou tanto interesse na comunidade internacional que o definiu como um fato histórico. $\mathrm{O}$ acordo foi assinado pelo Monsenhor Antoine Camilleri, Subsecretário para as Relaçôes da Santa Sé com os Estados e pelo Senhor Wang Chao, Vice- ministro dos Assuntos Exteriores da República Popular da China, respetivamente chefes das Delegaçôes vaticana e chinesa (SANTA SEDE, 2018). O comunicado evidenciou que a questão da nomeação dos bispos dizia respeito a uma questáo de grande relevo para a vida da Igreja e que o acordo criaria as condiçóes para uma mais ampla colaboração em nível bilateral (SANTA SEDE, 2018).

Apesar de o acordo tratar apenas de matéria religiosa, mesmo fundamental para a Igreja Católica, podemos entrever, portanto, desdobramentos mais amplos que dizem respeito também às relaçôes institucionais entre Santa Sé e China, como a futura retomada das relaçôes diplomáticas entra os dois estados.

O jornal chinês Global Times publicou dois dias depois uma matéria sobre o acordo apontando que seus resultados iam muito além da questâo da nomeação dos bispos chineses. Com efeito, o acordo demonstrou que as duas partes conseguiram superar preconceitos que impediam uma aproximação efetiva.

ao assinar o acordo provisório, os dois lados
superaram uma importante barreira cogni-
tiva. O Vaticano eliminou seu mal-entendi-
do anterior sobre o sistema social e político
chinês e a comunidade católica chinesa. [...]
Vaticano demonstrou muita sinceridade.
Por outro lado, a China também modificou
sua atitude em relaçáo ao Vaticano. A Chi-
na manterá seu princípio religioso de inde-
pendência e auto-gestáo, mas ao mesmo
tempo respeitará a prática internacional. É
por isso que as negociaçóes continuaram.
(CHENYAN, 2018)

O acordo sanciona a participação conjunta das duas partes na escolha dos bispos chineses. O lado chinês seleciona um candidato e o apresenta ao Papa que tem o poder de veto. O texto do acordo não foi publicado até o momento porque, por ser provisório, poderá ser reavaliado e revisado a qualquer momento. Como parte do acordo, o Papa Francisco reconheceu a legitimidade de sete bispos chineses que haviam sido nomeados apenas pelo governo chinês. Com este ato, acabaria, de acordo com o Car- 
deal Parolin, "a divisão até então existente entre bispos legítimos e ilegítimos" (PULLELLA, 2018). De agora em diante, todos os bispos da China estariam em comunhão com o Papa.

\section{Conclusões}

No dia 26 de setembro, Papa Francisco enviou uma mensagem aos católicos chineses e ao resto da Igreja Católica explicando o teor do acordo assinado poucos dias antes (FRANCISCO, 2018).

É importante evidenciar 03 pontos fundamentais dessa mensagem que podem nos ajudar a compreender as implicaçóes mais amplas deste acordo. O primeiro reitera a unidade da comunidade católica na China, ou seja reconhece a legitimidade da Igreja Oficial e de certa forma deslegitima o papel da Igreja Clandestina. Isso significaria que gradualmente a perseguição religiosa dos católicos por parte do governo de Pequim deveria se reduzir não tendo mais razão para continuar pois os membros da comunidade católica chinesa, seguindo as diretrizes do Papa Francisco poderiam se registrar junto ao governo sem ter medo de trair, com este ato, sua lealdade ao Papa.

Segundo, ele convida os católicos chineses a abraçar os projetos nacionalistas da China e trabalhar para o ressurgimento do país. Este convite é importante pois nos parece ir ao encontro do processo de sinacização das religióes na China anunciado por Xi Jinping durante o XIX Congresso do Partido Comunista e oficializado quando da publicação do Regulamento sobre Assuntos Religiosos publicado pelo governo em 2018.

Terceiro, e não menos importante, Francisco deixa aos católicos chineses a liberdade de poder contribuir de forma crítica mas respeitosa à construção de uma sociedade chinesa que respeite a dignidade de cada ser humano. Isso talvez seja a parte que o governo de Pequim menos aprecie, mas que descreve um papel que no discurso da Igreja Católica é irrenunciável, o de trabalhar para a plena realização do ser humano.

Portanto, o acordo garantiu aparentemente benefícios para ambas as partes. Como o Papa Francisco afirmou é um instrumento que náo poderá resolver todos os problemas existentes, mas certamente colocou as bases para uma aproximação mais profícua entre o menor estado do mundo e o gigante da Ásia.

\section{Referências}

AZEVEDO, Dermi. Desafios estratégicos da Igreja Católica. LUANOVA, n. 60, p. 57-79, 2003. Disponível em: <http:// www.scielo.br/pdf/\%0D/ln/n60/a04n60.pdf>. Acesso em: 30 set. 2018

BATES, Gill. China's future under Xi Jinping: challenges ahead. Political Science, 2017. Disponível em: <http:// sdsc.bellschool.anu.edu.au/sites/default/files/publications/ attachments/2017-06/bates_gill_-_china_s_future_under_xi_ jinping_challenges_ahead.pdf>. Acesso em: 23 maio 2018.

BECARD, Danielly S.; MENECHELLI, Paulo F. Chinese Cultural Diplomacy: instruments in China's strategy for international insertion in the 21st Century. Rev. Bras. Polit. Int., Brasília, v. 62, n. 1, 2019. Disponível em: $\quad<$ http://www.scielo.br/scielo.php?script=sci_arttext\&pid=S0034-73292019000100205>. Acesso em: 4 jul. 2019. BENTO XVI. Carta do Santo Padre Bento XVI aos Bispos, aos Presbíteros, às Pessoas Consagradas e aos fiéis leigos da Igreja Católica na República Popular da China. Libreria Editrice Vaticana, 27 maio 2007. Disponível em: <http://w2.vatican. $\mathrm{va} /$ content/benedict-xvi/pt/letters/2007/documents/hf_ben-xvi_let_20070527_china.html>. Acesso em: 10 ago. 2018.

CARLETTI, Anna. Diplomacia e Religião: encontros e desencontros entre a Santa Sé e a República Popular da China de 1949 a 2005. Brasília: FUNAG, 2008.

CARLETTI, Anna. O internacionalismo do Vaticano e a nova ordem mundial: a diplomacia pontifícia da Guerra Fria aos nossos dias. Brasília, FUNAG, 2012.

CHAMBON, Michel. The Holy See, China, and the question of sovereignty. La Croix, 20 feb. 2018. Disponível em: <https://international.la-croix.com/news/the-holy-see-china-and-the-question-of-sovereignty/6983>. Acesso em: 15 set. 2018. 
CHENYAN, K. Beijing-Vatican agreement good news for 6 million Chinese Catholics. Global Times, 28 set. 2018. Disponível em: <http://www.globaltimes.cn/content/1121341. shtml>. Acesso em: 13 maio 2019.

CHU, Lan T. Peace and Dialogue: The Faith Diplomacy of the Catholic Church in Historical Perspective. In: LEIGHT, Naomi (Ed). Essays on Faith Diplomacy. Los Angeles: Figueroa Press, p. 29-46, nov. 2011. Disponível em: <https://www. uscpublicdiplomacy.org/sites/uscpublicdiplomacy.org/files/ useruploads/u35361/2011\%20Paper\%208.pdf>. Acesso em: 10 maio 2019.

DENG XIAOCI. Planned China-Vatican exhibit a sign both sides moving to improve relations: experts. In: GLOBAL TIMES, 22/11/2017. Disponível em <http://www.globaltimes. cn/content/1076704.shtml>. Acesso em: 14 maio 2019.

ESTEBAN, Mario.Lapolítica exteriordeXiJinping trasel $19^{\circ} \mathrm{Con}-$ greso: China quiere un papel central en la escena global. ARI, v. 80, 25 oct. 2017. Disponível em: <http://www.realinstitutoelcano.org/ wps/wcm/connect/7c757bfa-7bda-49c1-8607-ae6b12412acc/ ARI80-2017-Esteban-politica-exterior-Xi-Jinping-19-Congreso-China-quiere-papel-central-escena-global.pdf?MOD=AJPERES \&CACHEID=7c757bfa-7bda-49c1-8607-ae6b12412acc>. Acesso em: 21 abr. 2019.

FRANCISCO. Mensagem do Papa Francisco aos Católicos Chineses e à Igreja Universal, 26 de Setembro de 2018. Disponivel em: <https://w2.vatican.va/content/francesco/pt/messages/pont-messages/2018/documents/papa-francesco_20180926_ messaggio-cattolici-cinesi.html> Acesso em: 30/09/18.

GLASER, B.; MURPHY, E. Soft power with Chinese characteristics. In: McGIFFERT, C. (Ed.). Chinese soft power and its implications for the United States: competition and cooperation in the developing world. Washington, DC: CSIS, p. 10-26, 2009. Disponível em: <https://csis-prod.s3.amazonaws. com/s3fs-public/legacy_files/files/media/csis/pubs/090403_ mcgiffert_chinesesoftpower_web.pdf $>$. Acesso em: 4 jul. 2019.

GLOBAL TIMES. El Papa debe aceptar la independência de la Iglesia china. AsiaNews, 04 fev. 2016. Disponível em:<http://www.asianews.it/noticias-es/Global-Times:-El-Papa-debeaceptar-la-independencia-de-la-Iglesia-china-36595.html>. Acesso em: 3 jun. 2019.

POPE URGES RESPECT for rights, justice and ethnic diversity in Myanmar speech. Global Times, 28 nov. 2017. Disponível em: <http://www.globaltimes.cn/content/1077697. shtml>. Acesso em: 4 jun. 2019.

LEIGHT, Naomi (Ed). Essays on Faith Diplomacy. Los Angeles: Figueroa Press, nov. 2011. Disponível em: <https:// www.uscpublicdiplomacy.org/sites/uscpublicdiplomacy.org/ files/useruploads/u35361/2011\%20Paper\%208.pdf>. Acesso em: 10 maio 2019.

LEUNG, Beatrice. China's Religious Freedom Policy: The Art of Managing Religious Activity. China Quarterly, 2005, 184: pp. 894-913.

OSMAN, Romana. China's soft power: an assessment of positive image building in the Middle East. 2017. 38f. Dissertação (Mestrado em Relaçóes Internacionais) - Universidade de Leiden, Leiden, 2017. Disponível em: <https://openaccess. leidenuniv.nl/bitstream/handle/1887/53153/final\%20thesis. pdf?sequence=1>. Acesso em: 13 maio 2019 .

PULLELLA, P. Corrected: Vatican, China sign landmark accord on appointing bishops. Reuters, 26 set. 2018. Disponível em: <https://in.reuters.com/article/pope-china/corrected-vatican-china-sign-landmark-accord-on-appointing-bishops-idINKCN1M607Y>. Acesso em: 29 set. 18.

QINGPING, Paul Han. Chinese Catholics don't understand criticising the Pope In: Settimana News, 1 Mar 2018. Disponível em: <http://www.settimananews.it/politica/the-holy-see-conference-gets-also-to-china/> Acesso em: 01/09/18

RAMACHANDRAN, Sudha. Rohingya Crisis: Will China's Mediation Succeed? China Brief, v. 17, issue 15, p. 8-12, 22 nov. 2017.

SANTA SEDE. Comunicado circa la firma di un Accordo Provvisorio tra la Santa Sede e la Repubblica Popolare Cinese sulla nomina dei Vescovi. 22 set. 2018. Disponível em: <https://press.vatican.va/content/salastampa/it/bollettino/pubblico/2018/09/22/0673/01468.html>. Acesso em: 30 maio 2019 .

SISCI, Francesco. China-Vaticano: vigília de um possível acordo. Insituto Humanitas Unisinos, 25 fev. 2018. Disponível em: <http://www.ihu.unisinos.br/78-noticias/576377-china-vaticano-vigilia-de-um-possivel-acordo-artigo-de-francesco-sisci>. Acesso em: 29 jul. 2018.

SISCI, Francesco. Pope Francis urges world not to fear China's rise: AT exclusive. Asia Times, 02 feb. 2016. Disponível em: <https://www.asiatimes.com/2016/02/opinion/at-exclusive-pope-francis-urges-world-not-to-fear-chinas-rise/>. Acesso em: 10 out. 2018.

ZHANG, Juyan. China's Faith Diplomacy: Initiatives and Vulnerabilities. LEIGHT, Naomi (Ed). Essays on Faith Diplomacy. Los Angeles: Figueroa Press, p. 47-66, nov. 2011. Disponível em: <https://www.uscpublicdiplomacy.org/sites/ uscpublicdiplomacy.org/files/useruploads/u35361/2011\%20 Paper\%208.pdf>. Acesso em: 10 maio 2019. 